\title{
Articles
}

\section{Dissertation 101: A Research and Writing Intervention for Education Graduate Students}

By Anne Switzer and Sherry Wynn Perdue

\begin{abstract}
The vast breadth of information sources available in the field of education and the dearth of institutional resources for native graduate writers have left many graduate students overwhelmed, struggling to conduct an exhaustive review of the literature and to compose their literature reviews. To remedy this concern, collaboration between library and writing center faculty resulted in Dissertation 101, a seminar designed for graduate education students who are about to commence research for this high-stakes document. Bolstering the connections between academic librarians, writing center faculty, and graduate students has proven effective in refining the information seeking, evaluation, and synthesis skills of graduate education students. The seminar, now in its second year, is presented as a model intervention, a first step toward greater institutional accountability for graduate student writers.
\end{abstract}

It would be ideal if education students embarked on their graduate careers with a strong grasp of information literacy concepts. However, as has become evident through the literature and our work with graduate education students in group instructional sessions and one-on-one consultations, their information literacy still needs to be addressed. In the age of Google, preparing lesson plans and classroom activities typically involves Internet research, as the Web has unlocked a multitude of teacher-oriented sites where practitioners share resources and experience. While such Internet searches plant the foundation of good (or bad) habits with respect to information literacy, even expert Web searching does not satisfy the competency standards as outlined by the Association of College and Research Libraries (ACRL). Information literacy is defined as a skill set enabling individuals to "recognize when information is needed and have the ability to locate, evaluate, and use effectively the needed information" (ACRL 2000, 2). The quandary is not that graduate education students are information deficient (they can generally find piles of information on a given topic in their field) but rather that they lack a clear understanding of research constraints and fail to compile peerreviewed scholarship, particularly seminal studies, that adequately represents existing expert knowledge. As a result, the novice researcher will be unable to proceed into the writing phase of the dissertation/thesis process.

Given the above difficulties and competency standards, the librarian's objective in this intervention is to accomplish the following: help emergent scholars to recognize their information needs before composing; demonstrate the best strategies for seeking and locating appropriate information; exemplify how to evaluate the relevancy of gathered information; and finally, illustrate how to use information effectively and how to cite all sources accurately and in accordance with the expected style guide.

\section{The Writing Concerns of Graduate Education Students}

Two of three graduate writers who visit the Oakland University Writing Center for assistance on their dissertation literature reviews struggle not only to conduct an exhaustive review of existing literature for relevant peer reviewed scholarship but also to synthesize this scholarship into a wellframed conversation about what the experts know. If this does not take place, individual authors cannot make a case for the efficacy of their 
scholarly contribution, which means they cannot defend the proposal and pursue the study. This difficulty confronting the task, however, should not been seen as an individual failure for many reasons, which will be detailed below.

A paucity of peer reviewed literature identifies the research and writing needs of graduate writers. While numerous dissertation advice books with titles like Surviving your dissertation: A comprehensive guide to content and process (2001), Authoring a PhD: How to plan, draft, write and finish a doctoral dissertation or thesis (2003), The dissertation journey: A practical and comprehensive guide to planning, writing, and defending your dissertation (2004), and Your PhD companion: A handy mix of practical tips, good advice and helpful commentary to see you through your PhD (2006) offer advice on how to draft a dissertation, Kamler (2008) has demonstrated the limitations of the dissertation advice genre as that which too often "normalizes the power-saturated relations of protégé and master" and offers a "rigid model of that dissertation that follows a set format and style," which may not be characteristic of all dissertation tasks (p. 507). In most cases, these texts exist for only one audience- the dissertation writer him/herself - further limiting their purview because the dissertation committee needs to better understand both the complexity of the task and the specific writing needs of the graduate student writer as s/he begins composing. While the search terms "dissertation supervision" yield some publications directed at faculty (such as Kamler's 2008 article), most that address writing either do so in a cursory way or they do little more than to lament the poor quality of graduate writing.

Unfortunately, this institutional neglect is characteristic of writing center scholarship too. A review of all articles in The Writing Center Journal, the only peer-reviewed publication in the field, yielded no articles that addressed the specific needs of native graduate writers. When the search was enlarged, only two ERIC articles were found, neither of which was published in a juried publication. After recognizing the difficulty of providing adequate support for graduate writers in her 1993 conference paper, Powers advocated a pedagogy of triangulation among graduate writer, dissertation chair, and writing center faculty. In 2005, Garbus addressed the issue, citing continued difficulties for graduate writers who find little institutional support for what they find to be a new and specific disciplinary task. She raises critical questions, such as "How do you write a literature review in your particular field? How do you synthesize and organize so much complicated information?" While these questions remain unanswered by writing center scholarship, the seminar we describe in this description of practice could precipitate a new examination of services that will redress this silence.

In lieu of evidence based practice that highlights discipline-specific, task specific graduate writing pedagogy and practice, most graduate writers are advised to read the defended manuscript of an advisor's student as a model for this process. The student reader is expected to infer important academic expectations. In some cases, the author has been advised by well-meaning faculty to draft summaries of each article, which they then link in a loose fashion, often without transitions that signal how one article is related to another. In this scheme, the literature review appears to restart examination of several literature talking points each time a new article is addressed. In sum, many graduate writers present an annotated bibliography at their initial consultation genuinely believing that it is a literature review. Unfortunately, an annotated bibliography does not place the literature within the context of an ongoing discussion.

Often by the time a graduate student reaches the writing center, s/he has already composed the skeleton of two chapters, neither of which is viewed as acceptable to the thesis/dissertation director who in a frustrated dismissal or in a kind gesture suggests "go to the library/writing center." While librarians and consultants can intervene at this moment, dissertation inertia may have already set in. In such cases, the discouraged graduate writer may delay making that appointment, which could jeopardize the timeliness of the reviewed 
literature and lead to further delays when and if the graduate writer returns to the project. Given all of the above challenges, the writing faculty's seminar objective is:

- To redress the belief that academic [research and] writing is a "solitary activity for which students already are prepared" (Mullen 2006, p.30; Wasby 2001);

- To acknowledge where graduate writers enter and where they must leave: "Graduate students are novice researchers and writers who must be initiated into the culture of academic writing" (Mullen 2006, p. 30);

- To address the importance of careful committee instruction by allowing attendees to learn vicariously from the missteps of others; and

- To offer discipline specific instruction on synthesizing a juried literature review, which is distinct from assembling an annotated bibliography or from drafting a teaching reflection.

\section{Literature Review}

While higher education in the United States emphasizes writing within the undergraduate curriculum and institutional support for the undergraduate research writer, the needs of graduate dissertation writers often go unmet and largely remain undocumented in scholarly research (DiPierro 2007; Lee and Aitchison 2009). This institutional and disciplinary neglect has dire consequences for graduate students, their supervising faculty, the disciplines in which they compose, and the institution.

Depending upon the estimates, postcomprehensive doctoral program attrition hovers around 50\% (DiPierro 2007). While this attrition too often has been attributed solely to a weakness within an individual student, researchers now cite other contributing factors. For example, Caffarella and Barnett (2000) acknowledge that attempts to introduce the "scholarly writing process often come in the form of "too little too late,", potentially not until students begin drafting their dissertations (p.39). The authors further demonstrate that scholarship has failed to examine how graduate students perceive their task as writers. As a result, doctoral students often "struggle in silence with issues of developing a proposal or writing a literature review, and new advisors, with little more than their own dissertation experience to serve as guide, frequently discover themselves as denizens in uncertain worlds" (DiPiero 2007, pp. 369-370).

This ambiguity of role and route to task is further complicated by the lack of formal research and writing education for advisors in their role as dissertation supervisors, which DiPierro, Director of Western Michigan's Graduate Center for Research, Writing, and Proposal Development, implicates as the root of potential communication problems between advisor and advisee (2007). There is little support for graduate faculty, few scholarly publications exist to guide faculty as they fulfill this task, and dissertation supervision is not rewarded within most institutions (Boud and Lee 2009).

To further exacerbate the problem facing the dissertation writer and her advisor, the literature review (the focus of the Dissertation 101 Seminar) is the least well understood, supported, and assessed component of the U.S. education dissertation (Boote and Beile 2005). Boote and Beile (2005) note that U.S. training in education focuses primarily on methodology and epistemology; "standards for a high quality literature review are not part of the formal curriculum of graduation expectations of even nationally ranked doctoral programs" (2005, p. 10). Their research yielded a dearth of research on both the literature review and its place in the graduate program. Of that which they did find, Boote and Beile demonstrate that faculty attitudes about the literature review in relationship to other dissertation chapters (members placed it last) reinforced its low status. The authors opine that this lack of institutional attention explains why education literature reviews were often found to be little more than poorly conceived "bits and pieces of a disorganized topic" (p.3), findings that complement complaints made by editors and 
reviewers about coverage of the professional literature within new submissions to education journals (p.4).

A citation analysis of graduate literature reviews likewise signals problems with graduate students' information literacy skills (Beile, Boote, and Killingsworth 2004). Beile, Boote, and Killingsworth (2004) queried source quality and comprehensiveness of dissertation literature reviews, finding that students in all institution types "cited a remarkable number of sources of questionable quality" and that selection criteria was highly influenced by what was locally owned (2004, p. 353). Such studies challenge the belief that dissertation writers are capable of making choices about the literature that reflect what is scholarly, current, and appropriate for their research.

If the literature review is to serve its purpose, Boote and Beile (2005) argue that it must demonstrate that the graduate researcher has done the following: 1) "thoroughly mined the existing literature and purposefully decided what to review" (p.7); 2) reshaped it into a synthesis that demonstrates what the experts know; and 3) made the case that the student researcher's own study will complement, contest, or fill a gap in prior research. This is the task of Dissertation 101: to introduce graduate researchers to the advanced information literacy skills needed to cull the literature and to craft a literature review that adequately represents existing knowledge and justifies the student's dissertation study.

Finally, while not adequately addressed, the literature does reveal that dissertation intervention must be audience-, discipline- and task- specific (Kamler 2008). Librarians Switzer and Lepkowski (2007) demonstrate that graduate students have different information literacy and writing needs than undergraduates. Grafstein (2002), Hook (2005), and Witt (2003) document increased need for collaboration between libraries and writing centers to meet those needs. They likewise address the importance of discipline specific instruction for graduate education writers. Garbus (2005) and
Powers (1993) explore other forms of collaboration - triangulated writing center consultations that involve writing expert (writing center faculty), disciplinary representative (dissertation director), and the graduate studentthat might yield better graduate writing.

The rest of this paper describes a seminar designed to address the information literacy and writing needs of graduate education writers at Oakland University.

\section{The Seminar: Librarian: Recognizing Information Needs}

The first competency standard for an information literate individual (at a higher education level) defined by the ACRL is: The information literate student determines the nature and extent of the information needed (ACRL 2000, p. 8). In the case of graduate education students, it is often their own classroom teaching experiences that shape and help articulate a research problem. The trouble with this method of identifying a research topic is that education graduate students often lack enough knowledge of the existing scholarship to determine whether their chosen problem represents a gap in the literature or simply a gap in their own understanding of the issue.

Consequently, many students need training in the fundamentals of research writing before they can successfully embark on their own scholarly pursuits.

The seminar librarian discusses the importance of understanding key scholarly concepts, such as "comprehensive literature review," "seminal studies," and "peer-reviewed," through which experts in the field propagate information. Grasping the aforementioned concepts is the first step in understanding the information needed to develop a focused research topic and offers an introduction to research in the discipline. Participants are also directed to interrogate the efficacy of different types of information resources (e.g., popular vs. scholarly and the value of historic vs. current scholarship) for their literature reviews. While these distinctions may seem unnecessary for this audience, it is actually 
more relevant to graduate students than to undergraduate students who usually get this training before they actually need to employ it in a high stakes document. Once graduate students understand these distinctions, they are less likely to settle for what is readily available, and they express more willingness to request items via interlibrary loan, another resource the librarian introduces.

\section{Refining Search Strategies to Seek and Locate Information}

The second information literacy standard as outlined by the ACRL is: The information literate student accesses needed information effectively and efficiently (ACRL 2000, p. 9). Graduate level research for education students is dependent upon identifying relevant databases for use in education. The seminar librarian models searching in a variety of databases such as ERIC, PsychINFO, JSTOR, Project Muse, and Dissertation Abstracts, with an emphasis on more sophisticated ERIC features. While most graduate education students are familiar with ERIC, seminar participants are often unaware of ERIC's more advanced functions. Proficiency with the more advanced search tools, such as the thesaurus (where the descriptors are indexed), grade-level delimiters, document-type delimiters, and other features designed to help a researcher narrow or expand a search, is a primary goal of the seminar librarian's portion of the intervention. Mastering ERIC's controlled vocabulary is essential to constructing and refining effective searches. Discussion indicates that prior to the seminar students may have chosen key terms based on terminology used by professors, their school principal, textbook, or the newest jargon generated by educational professionals. By utilizing ERIC descriptors, a researcher will find words and phrases assigned to ERIC records, which will provide more precise search results. Understanding the difference between keyword and descriptor searching saves researchers time and frustration. For example, the keywords "emotionally impaired" are commonly used by educational professionals to describe persistent, serious emotional disorders resulting in behavioral problems. The ERIC database, however, has assigned articles and records related to this concept with the descriptor term "Emotional Disturbances," (entering "emotionally impaired" into the ERIC thesaurus brings one to an alphabetized list of terms and related terms, including a hierarchical list of specific diagnoses falling under the umbrella of "Emotional Disturbances"). In this example, using the descriptor will yield far more relevant results than the keywords "emotionally impaired." In addition, this hierarchical list functions as a brainstorming tool by providing connected concepts.

Seminar students are also given a demonstration on finding relevant dissertations using Dissertation Abstracts via First Search. Many graduate students are unaware that they can initiate an interlibrary loan request to obtain a scanned copy of a dissertation indexed in this database. Such material may provide an excellent model for their research, not only in terms of structure, but also as an example of studies that their advisors have previously authorized. Because dissertations are not as readily available and because undergraduates do not encounter them much during their information literacy training, graduate students often fail to consult the best model available, and that is something we seek to change.

Utilizing a variety of databases is another concept emphasized by the seminar librarian. The nature of many education theses is cross-disciplinary, for example, special education topics such as attention deficit disorder or autism cross into psychology. Therefore, to thoroughly research such topics, one must explore non-education databases, such as PsychInfo, PsychArticles, and Mental Measurements Yearbook. Many database platforms, such as CSA and FirstSearch, allow for simultaneously searching multiple databases. Dissertation writers need to be aware of these tools to ensure that they find all relevant studies on their topics.

\section{Evaluating the Information}

The third information literacy standard outlined by the ACRL is: The information literate student

Education Libraries, Volume 34, Number 1, Summer 2011 
evaluates information and its sources critically and incorporates selected information into his or her knowledge base and value system (ACRL 2000, p. 11). The outcome for this standard is apparent through the successful writing of a researcher's literature review. First, the dissertation writer must become skilled at making informed distinctions among the many different types of education resources and become practiced at discerning which materials have been submitted by practitioners and which are published journal articles in scholarly periodicals. The heterogeneity of the ERIC database can be especially difficult for the novice researcher to discern. Understanding the peer-review process and the various methods employed in creating ERIC documents, as well as the criteria by which such submissions are chosen for inclusion, is essential in learning to recognize the distinctions among different types of content.

Additionally, the seminar librarian explains that even when a source is from a peer-reviewed publication, the article itself may not be a research article. As such, the librarian addresses such works as book reviews, editorials, personal essays, etc. She also demonstrates how to use Ulrich's Periodical Directory, which helps researchers to determine which of their sources are indeed contained in juried publications.

Because some topic searches yield more studies than others, the librarian also models how to use the Cited Reference Search feature of ISI Web of Science. This helps dissertation writers determine the seminal studies related to their research. Cited reference searching is a useful strategy for tracking the scholarly debate on a particular topic, but novice researchers are warned about relying too heavily on this method. In other words, to conduct an entire thesis literature review from the research of other scholarship is not advisable for a variety of reasons. The ISI cannot track all journals, so depending on one's topic, a seminal study may be overlooked unless one consults a variety of databases. Recent research may be missed because it has not yet been indexed or cited. The "impact factor" can be skewed when scholars self-cite. Cited reference searching is not all inclusive - books and book chapters are omitted from ISI (for this reason, Google Scholar is also demoed during the seminar because they include books and book chapters). Additionally, mistakes can be made in the tracking of citations and in the forming of the citation itself. All of these caveats should dissuade researchers from using the cited reference search as an exclusive, or even primary, search strategy, but rather it should be used as a tool for tracking seminal works.

In addition to evaluating the information sources critically, information literate researchers, as the ACRL criteria recommends, should be able to incorporate the found resources into their own knowledge base. Therefore, a well-written literature review will reflect not only the accumulation of information but also a synthesis of that information. Quotes should be accurate and used sparingly; the writing should demonstrate an emphasis on restating concepts from the material into the writer's own words. A thorough examination and comparison of resources ought to be apparent from researcher's literature review. It is also important that a dissertation writer's synthesis contain original concepts, which will ideally offer something new to the discipline's scholarly debate.

\section{Using Information Effectively}

The fourth competency standard outlined by the ACRL is: The information literate student, individually or as a member of a group, uses information effectively to accomplish a specific purpose (ACRL 2000, p. 13). This standard, for the purposes of our seminar participants, is a thorough and complete literature review. The intended audience clearly dictates the form and style, which the researcher must employ to demonstrate effective use of information. The organization and articulation of the found knowledge is integrated into a new context and passed to a writer's advisor for approval. Those researchers who do not meet this standard join the many education graduate students who finish their coursework but who do not earn a degree because their dissertation remains incomplete. Therefore, 
meeting this standard is at the crux of each goal outlined for this seminar.

\section{Using Information Ethically}

The final competency standard outlined by the ACRL is: "The information literate student understands many of the economic, legal, and social issues surrounding the use of information and accesses and uses information ethically and legally" (ACRL 2000, p. 14). The importance of fulfilling this competency standard is emphasized strongly throughout the seminar. It is often presumed that graduate level students understand the differences between access to free and feebased information and the rules of quoting and paraphrasing, which are further addressed by the writing center faculty member.

\section{The Seminar: Writing Faculty Committee Construction}

A comprehensive search of available literature should be nearly complete by the time participants consider many of the issues addressed in the second half of the seminar. The writing faculty begins her presentation by stressing the importance of one issue that predates the research and writing: selecting a chair and compiling a committee. She asks participants to consider faculty members with whom they learned the most and worked best. She poses such questions as whether each was good at giving feedback and returning projects in a timely manner or whether $\mathrm{s} /$ he would work well with other potential committee members. Can s/he serve as both a coach and a buffer as needed? This discussion is important because graduate students need a safe forum in which to discuss the politics of committees. Of additional committee members, she encourages participants to consider whether or not these faculty members know the student's work and that of the chair. Will their expertise complement the project? Can they work well with and defer to the chair? Will they meet with the dissertation writer before $\mathrm{s} / \mathrm{he}$ drafts the proposal to offer guidance? And most importantly, do the committee members understand and respect the student's methodology?
These issues must be addressed early because the literature indicates that graduate students aren't privy to the fact that most committee members have little experience in how to help a student write such a high stakes document except for having written one themselves. While the literature designed to help graduate students complete their dissertations examines committee assembly, too often it is done with the suggestion that graduate students have the power to negotiate these hurdles (Kamler 2008). Further, as previously noted, too little of that scholarship is directed at the committee itself. As such, we seek to alert students to the possibility of committee difficulties and to offer our offices as potential sites of intervention.

\section{An Assignment like No Other}

As a writing center director and a faculty member who has reviewed hundreds of graduate course syllabi and assignments, the presenter also cautions participants to understand that the papers they have composed for their professors are generally unlike a dissertation (Wasby 2001). Reflections on practice, explanations of pedagogical choices, position statements, theoretical treatises, and lesson plans are not academic syntheses followed by one's own primary research, the cornerstone of the social science dissertation. While course papers in the humanities are often adapted into dissertations because: 1) they generally don't present the student's own research, 2) they don't include stand alone literature reviews, and 3) they can take an inductive approach to explore a theory, those produced in social sciences classes like education generally are not. These disciple-specific challenges must be articulated and discussed if a dissertation intervention is to succeed.

\section{Scope of the Literature Review}

After addressing the politics of committee assembly and the rhetorical purpose of a social science dissertation as distinct from classroom assignments, the writing center faculty member offers specific guidance on how to cull and synthesize the compiled literature for a specific audience: the committee and the discipline. The 
first challenge is to help the writer understand the purpose and scope of a literature review. Too often, the audience does not comprehend the difference between an annotated bibliography and a synthesis of the literature. The number one difficulty she has observed in dissertation consultations over this document is a list of article abstracts strung together as a literature review. The presenter offers such examples as an opportunity from which to learn vicariously. Noting the problem is just one part of the correction, however. Students need a tangible concept of the literature review, which the presenter offers in the following definition: The literature review is a professional conversation framed by a guiding concept, a well-organized presentation of the current state of topic knowledge, designed to highlight past research findings and to pave the way for the current research. Its characteristics as presented follow:

- An introduction that shares the persistent question(s) the reviewed literature will address and indicates how the reviewed scholarship will be framed

- An organizational frame, which groups relevant scholarship by topic, chronology, theoretical approach, methodology, etc. and/or a combination of approaches

- Transitions organic to the discussion that indicate how different studies approach the same issues both within individual paragraphs and between paragraphs (rather than relying too heavily on headers to do all the work)

- Evidence of how conflicting findings within the literature might be resolved by looking at the methodology, sample size, questions asked (and not asked), etc.

- A conclusion that clarifies how the literature demonstrates the efficacy of the dissertation study. Does it demonstrate a gap in the literature? Does it identify a conflict that needs resolution? In many cases the specific research questions for the student author's proposed study will be shared here too.

\section{A Rubric for Synthesis: The Source Grid} Offering a definition that examines the parts in relation to the whole is essential, but the presenter also offers a tangible rubric for drafting this highstakes document. Several years ago she created a graphic organizer entitled the source grid, which she has used successfully with hundreds of undergraduate and graduate students at Oakland University (See Table 1). In short, this document is a table that could be constructed as a Word or Excel file. The first column contains each source citation. It further indicates whether or not the text is peer reviewed and if it is a seminal work. Column two contains a source summary. Subsequent columns are occupied by "talking points," defined as recurrent issues in the professional literature that will form major sections of the literature review.

Once the dissertation writer has determined the issues that occur frequently in the literature, $\mathrm{s} / \mathrm{he}$ is ready to start entering data into the organizer. The rows are occupied by individual sources and the insight they provide to each talking point. The student enters paraphrases, quotes, and statistics for each talking point (not all articles will address every talking point) along with a page or paragraph reference number. Once the source grid is complete, the dissertation writer is ready to begin composing in a piecemeal or quilting fashion. Each column becomes a section of the dissertation, which is transferred into a word file. The author writes the literature review section-bysection. Because s/he can see how several authors address the same issue, more sources will likely be used, better credentialing the study, and the text is more likely to be shaped by the issues rather than driven by sources. The source grid offers several advantages to a traditional outline. It allows the student researcher to recognize gaps in desired coverage before the writing begins. During the drafting stage the source grid encourages better paraphrasing, potentially reducing "patching," because the author can see the original text or several versions of the same point as $\mathrm{s} /$ he starts to write. It keeps the writer focused on ideas rather than simply summarizing the study and results of each cited study. Further, because it does not

Education Libraries, Volume 34, Number 1, Summer 2011 
prescribe a linear progression for the literature review, it allows the author to determine the order in which the parts should come together after each section has been composed. Transitions are added after the sections are drafted and arranged, which encourages the author to make them organic to the discussion rather than simply enumerating them.

\section{Conclusions and Implications}

Because many of the dissertation writers we encountered were stymied by their inability to research their topics in a systematic and exhaustive manner, we turned to ACRL criteria for information literacy. It is our contention that dissertation writers can become proficient researchers. Information literacy improves analytical skills, thus enabling writers to craft literature reviews that integrate their understanding of existing scholarship within the framework of their theses.

Furthermore, the struggling dissertation writers we encounter often lack the writing proficiency to compile effective literature reviews. A disjointed, summary-based document reflects an unclear understanding of its purpose, which is to frame the existing literature and to draw attention to gaps or inconsistencies within it that justify the graduate student's own study. This is accomplished via analysis, synthesis, and evaluation, skills that are addressed within our seminar.

It is our hope that upon completing the Dissertation 101 seminar, graduate writers will successfully transition from students who can complete course assignments to scholars who can make a contribution to their respective fields. While we know that the need exists (registration requests exceed capacity), we are just beginning to formally measure the impact of this endeavor. To that end, we are embarking on a study to assess the degree to which this seminar and other dissertation interventions have influenced graduate education student completion rates. Further, we plan to use citation analysis, faculty surveys, and institutional data to determine if the quality of the participant submitted literature reviews has demonstrated measurable improvement.
While the research to support the efficacy of this program is not yet complete, we cite the pedagogical influence of our program. Some education faculty members at our institution have already embedded elements of the seminar (such as requiring students to create a source grid in developing their literature reviews) into their courses. One is also documenting the effect of this tool on her students' success, which may also be demonstrated in future publications.

With the aforementioned in mind, we have made plans to extend this seminar to other disciplines. Because information literacy and academic writing is crucial in all areas of academia, this seminar and research that affirms its efficacy could provide a campus-wide opportunity to build relationships between the writing center, the library, and disciplinary graduate programs.

\section{References}

Association of College and Research Libraries. (2000). Information literacy competency standards for higher education. Chicago: ACRL. Retrieved from http://www.ala.org.huaryu.kl.oakland.edu/ala/acrl/ acrlstandards/informationliteracy-competency.htm

Beile, P. M., Boote, D. N., \& Killingsworth, E. K. (2004, September). A microscope or a mirror? A question of study validity regarding the use of dissertation citation analysis for evaluating research collections. Journal of Academic Librarianship, 30(5), 347-353.

Boote, D. N. \& Beile, P. (2005, August/September). Scholars before researchers: On the centrality of the dissertation literature review in research preparation. Educational Researcher, 34(6), 3-15.

Boud, D. \& Lee, A, eds. (2009). Changing practices of doctoral education. London: Routledge.

Caffarella, R. S. \& Barnett, B. G. (2000). Teaching doctoral students to become scholarly writers: The importance of giving and receiving critiques. Studies in Higher Education, 25(1), 39-52.

DiPierro, M. (2007, June). Excellence in doctoral education: Defining best practices. College Student Journal 41(2), 368-375. 
Garbus, J. (2005, fall). Tutoring graduate students in the writing center. Academic Exchange Quarterly. Retrieved January 26, 2010 from http://www.thefreelibrary.com/Tutoring graduate students in the writing center.-a0138703683

Grafstein, A. (2002). A discipline-based approach to information literacy. Journal of Academic Librarianship, 28(4), 197-204.

Hook, S. (2005).Teaching librarians and writing center professionals in collaboration: Complementary practices. In J.K. Elmborg \& S. Hook (Eds.), Center for learning: Writing centers and libraries in collaboration (pp. 21-41). Chicago, IL:

Association of College and Research Libraries.

Kamler, B., \& Thomson, P. (2008). The failure of dissertation advice books: Toward alternative pedagogies for doctoral writing. Educational Researcher, 37(8), 507-514.

Lee, A., \& Aitchison, C. (2009). Writing for the doctorate and beyond. In Boud, D. \& Lee, A. (Eds.). Changing practices of doctoral education. London: Routledge.

Mullen, C. A. (2006, fall). Best writing practices for graduate students: Reducing the discomfort of the blank screen. Kappa Delta Pi Record, 43(1), 3035 .

Powers, J.K. (1993, April). Helping the graduate thesis writer through faculty and writing center collaboration. Paper presented at the Annual Meeting of the Conference on College Composition and Communication $\left(44^{\text {th }}\right)$, San Diego, CA. (ERIC Document Reproduction Service No. ED358466)
Switzer, A.T. \& Lepkowski, F.J. (2007). Information literacy and the returning Master's student: Observations from the library side. In Proceedings of Society for Information Technology and Teacher Education International Conference, March 26-30, pp/ 1343-1348. San Antonio, TX: Association for the Advancement of Computing in Education.

Wasby, S.L. (2001, June). Proposal writing: A remedy for a missing part of graduate training. Political Science and Politics, 34(2), 309-13.

Witt, S.W., \& Dickinson, J.B. (2003). Teaching teachers to teach: Collaborating with a university education department to teach skills in information literacy pedagogy. Behavioral \& Social Sciences Librarian, 22(1), 75-95.

Anne Switzer

Information Services \& Outreach Librarian Assistant Professor

Kresge Library, Room 239

Oakland University

Rochester, MI 48309-4484

switzer2@oakland.edu

Sherry Wynn Perdue

Director of Oakland University's Writing Center

Oakland University

Rochester, MI 48309-4484

wynn@oakland.edu 
Table 1

\section{Source Grid}

\begin{tabular}{|c|c|c|c|c|c|}
\hline $\begin{array}{l}\text { Source Citation } \\
\text { w/peer review and } \\
\text { ranking information }\end{array}$ & $\begin{array}{l}\text { Source } \\
\text { Summary: } \\
\text { Omitted } \\
\text { because of } \\
\text { space } \\
\text { constraints. }\end{array}$ & $\begin{array}{l}\text { Talking Point One: While UG } \\
\text { writing is the focus of } \\
\text { American institutional writing } \\
\text { curriculum and support } \\
\text { services, the needs of graduate } \\
\text { writers often go unmet. }\end{array}$ & $\begin{array}{l}\text { Talking Point Two The } \\
\text { education literature } \\
\text { review is potentially } \\
\text { undervalued and poorly } \\
\text { assessed. Students' } \\
\text { prior coursework has } \\
\text { not prepared them for } \\
\text { the task, and instructor } \\
\text { feedback has not } \\
\text { centered on this } \\
\text { document. }\end{array}$ & $\begin{array}{l}\text { Talking Point Three } \\
\text { Graduate committee } \\
\text { members-those who } \\
\text { supervise the dissertation } \\
\text { and deem it acceptable-- } \\
\text { have little formal training } \\
\text { in advising the dissertation } \\
\text { writing process beyond } \\
\text { having written a } \\
\text { dissertation themselves. }\end{array}$ & $\begin{array}{l}\text { Talking Point Four: } \\
\text { While existing } \\
\text { institutional } \\
\text { resources, such as } \\
\text { writing centers and } \\
\text { libraries, are not } \\
\text { always well equipped } \\
\text { to serve the specific } \\
\text { needs of graduate } \\
\text { student writers, } \\
\text { recent scholarship } \\
\text { calls for more } \\
\text { collaboration } \\
\text { between the two to } \\
\text { serve graduate } \\
\text { writers. }\end{array}$ \\
\hline $\begin{array}{l}\text { Beile, P. M., Boote, } \\
\text { D. N., \& } \\
\text { Killingsworth, E. K. } \\
\text { (2004, September). A } \\
\text { microscope or a } \\
\text { mirror? A question of } \\
\text { study validity } \\
\text { regarding the use of } \\
\text { dissertation citation } \\
\text { analysis for evaluating } \\
\text { research collections. } \\
\text { Journal of Academic } \\
\text { Librarianship, 30(5), } \\
\text { 347-353. } \\
\text { Status: Refereed }\end{array}$ & & & $\begin{array}{l}\text { Citation analysis yields } \\
\text { an important challenge to } \\
\text { the belief that } \\
\text { dissertations reflect an } \\
\text { exhaustive review of } \\
\text { available literature. The } \\
\text { authors find that } \\
\text { dissertations tend to } \\
\text { reflect only the } \\
\text { publications available in } \\
\text { their institutions } \\
\text { scholarly databases, } \\
\text { which may unnecessarily } \\
\text { protract what writers find } \\
\text { and cite. }\end{array}$ & & \\
\hline $\begin{array}{l}\text { Boote, D. N. \& Beile, } \\
\text { P. (2005, August/ } \\
\text { September). Scholars } \\
\text { before researchers: On } \\
\text { the centrality of the } \\
\text { dissertation literature } \\
\text { review in research } \\
\text { preparation. } \\
\text { Educational } \\
\text { Researchers, 34(6), 3- } \\
15 . \\
\text { Status: Refereed }\end{array}$ & & $\begin{array}{l}\text { "The U.S. literature on the } \\
\text { education doctorate is } \\
\text { reminiscent of the early research } \\
\text { on learning to teach (Widen, } \\
\text { Mayer-Smith, \& Moon, 1999); } \\
\text { with little or no support from } \\
\text { solid data, the authors rely on } \\
\text { their personal prestige to discuss } \\
\text { problems of practice and make } \\
\text { recommendations for } \\
\text { improvements. But like the } \\
\text { literature on learning to teach, } \\
\text { the literature on learning to } \\
\text { research must move from } \\
\text { anecdotes, generalization, and } \\
\text { reports of programs to } \\
\text { systematic investigation and } \\
\text { recommendations based on } \\
\text { evidence" (5). }\end{array}$ & $\begin{array}{l}\text { Literature reviews } \\
\text { examined in their study } \\
\text { revealed "bits and pieces } \\
\text { of a disorganized topic" } \\
\text { (3). Authors opine that } \\
\text { the higher education } \\
\text { community has failed to } \\
\text { emphasize the literature } \\
\text { review: "We then argue } \\
\text { that current initiatives } \\
\text { and faculty focuses have } \\
\text { ignored the centrality of } \\
\text { the literature review in } \\
\text { research preparation, in } \\
\text { turn weakening the } \\
\text { quality of education } \\
\text { research" (3). } \\
\text { "The academic } \\
\text { community ought to be } \\
\text { able to assume that a } \\
\text { dissertation literature } \\
\text { review indicates a } \\
\text { doctoral candidate's } \\
\text { ability to locate and } \\
\text { evaluate scholarly } \\
\text { information and to } \\
\text { synthesize research in his } \\
\text { or her field" (4) }\end{array}$ & $\begin{array}{l}\text { "Yet, the most obvious } \\
\text { means of improving the } \\
\text { situation-adding a class on } \\
\text { literature reviewing to } \\
\text { doctoral programs - is the } \\
\text { least likely to be effective. } \\
\text { Such a curricular solution, as } \\
\text { Britzman (1991) noted about } \\
\text { learning to teach, would } \\
\text { leave the hardest task- } \\
\text { integrating and applying the } \\
\text { lessons from various classes } \\
\text { in the doctoral program-to } \\
\text { those who are least capable } \\
\text { of doing it. That is, to review } \\
\text { the literature in the way that } \\
\text { we have suggested here is a } \\
\text { very complex task that } \\
\text { requires the integration and } \\
\text { application of a variety of } \\
\text { skills and knowledge that } \\
\text { few individual faculty } \\
\text { members have mastered" } \\
\text { (11). }\end{array}$ & $\begin{array}{l}\text { "The new focus on } \\
\text { libraries on teaching } \\
\text { students to critically } \\
\text { engage with } \\
\text { information offers the } \\
\text { possibility of } \\
\text { successful faculty- } \\
\text { librarian collaboration, } \\
\text { especially in the realm } \\
\text { of graduate literature } \\
\text { reviewing and } \\
\text { writing" (12). }\end{array}$ \\
\hline
\end{tabular}

